\title{
Cognitive functioning and pain reactions in hospitalized elders
}

\author{
Thomas Hadjistavropoulos $\mathrm{PhD}^{1}$, Diane LaChapelle MA ${ }^{1}$, Farley MacLeod BSc(Hons) ${ }^{1}$, Carla Hale BA (Hons) ${ }^{1}$, \\ Norm O'Rourke $\mathrm{MA}^{2}$, Kenneth D Craig $\mathrm{PhD}^{3}$
}

\section{T Hadjistavropoulos, D LaChapelle, F MacLeod, C Hale, N O'Rourke, KD Craig. \\ Cognitive functioning and pain reactions in hospitalized elders.}

Pain Res Manage 1998;3(3):145-151.

BACKGROUND: Objectively coded facial activity provides a useful index of pain among elders who have difficulty in reporting pain because of cognitive impairments. However, limitations of previous research include no direct assessment of participants' level of cognitive impairment; no comparison of the reactions of elders with cognitive impairments with those of nonimpaired elders; observers' expectations about pain levels could have influenced judgements about the severity of pain experienced when global rather than objectively coded measures were used because the painful medical procedure was visible on film.

OBJECTIVE: To extend previous findings by incorporating improvements in design and methodology in response to the aforementioned limitations.

PARTICIPANTS: Fifty-nine in-patients with a mean age of 73 years.

METHODS: Facial reactions were filmed during routine blood tests and coded objectively using the Facial Action Coding System (FACS). Observer ratings of pain were also obtained.

RESULTS: FACS indexes revealed substantial changes from baseline to venepuncture indiscriminate of whether elders were cognitively impaired. Furthermore, these changes were apparent to both nurse and student observers although the nurses rated the pain displayed by the patients as being lower.
CONCLUSION: After addressing limitations of previous work in this area, the validity of nonverbal indexes of pain in the assessment of elders with cognitive impairments was demonstrated. Such indexes are uniquely suited as outcome measures within the context of clinical trial methodology.

Key Words: Elders, Nonverbal expressions, Pain measurement

\section{Fonctionnement cognitif et réactions à la douleur chez les personnes âgées hospitalisées}

HISTORIQUE : Les mouvements faciaux codés de façon objective fournissent un index utile de la douleur chez les personnes âgées qui ont de la difficulté à signaler leur douleur à cause d'une atteinte cognitive. Cependant, les limites des recherches antérieures comprennent une absence d'évaluation directe du niveau de l'atteinte cognitive des participants et l'absence d'une comparaison des réactions des personnes âgées atteintes de troubles cognitifs avec celles ne présentant pas de troubles cognitifs ; en outre, les attentes des observateurs concernant les niveaux de la douleur pourraient avoir influencé les jugements sur l'intensité de la douleur ressentie quand on a eu recours à des mesures codées de façon globale plutôt qu' objective parce que le film témoignait d'un examen médical douloureux.

OBJECTIF : Étoffer les données antérieures en incorporant des améliorations apportées au modèle et à la méthodologie en réponse aux carences mentionnées ci-dessus.

PARTICIPANTS : Cinquante-neuf patients hospitalisés âgés en moyenne de 73 ans.

voir page suivante

The order of authorship for the third and fourth authors was determined by draw

A portion of this paper was presented at the 1998 Convention of the Canadian Psychological Association (Edmonton, Alberta)

${ }^{1}$ Department of Psychology, University of Regina, Regina, Saskatchewan; ${ }^{2}$ School of Psychology, University of Ottawa, Ottawa, Ontario;

${ }^{3}$ Department of Psychology, University of British Columbia, Vancouver, British Columbia

Correspondence and reprints: Dr Thomas Hadjistavropoulos, Department of Psychology, University of Regina, Regina, Saskatchewan S4S OA2.

Telephone 306-585-4457, fax 306-585-4827, e-mail Thomas.Hadjistavropoulos@uregina.ca

Received for publication April 8, 1998. Accepted August 5, 1998 
MÉTHODES : Les mouvements faciaux des patients ont été filmés au cours de prélèvements sanguins de routine et codés objectivement en utilisant le FACS (Facial Action Coding System). On a aussi obtenu les cotations de la douleur faites par les observateurs.

RÉSULTATS : Les index du FACS on révélé des changements importants à partir des valeurs de référence jusqu'à la ponction veineuse sans distinction entre les personnes âgées atteintes ou non atteintes d'un déficit cognitif. De plus, ces changements ont été remarqués à la fois par les observateurs étudiants et infirmiers bien que les infirmiers aient coté à la baisse la douleur montrée par les patients. CONCLUSION : Après s'être penchés sur les limites des études antérieures dans ce domaine, la validité des index non verbaux de la douleur dans l'évaluation des personnes âgées atteintes d'un déficit cognitif a été démontrée. Ce type d'index convient exceptionnellement comme mesures des résultats dans le contexte d'une méthodologie d'essai clinique.
$\mathrm{O}$ ur limited ability to assess pain accurately in populations with severe neurological impairments can lead to insufficient attention to pain and medical catastrophes (1). Although pain in the elderly is very prevalent $(2,3)$, research suggests that physicians often fail to detect pain in elders with neurological diagnoses (4). Parmelee and colleagues (5) reported a small but significant negative relationship between reported pain and cognitive functioning in elders, with the association maintained even when the number of health problems was controlled. Elders with cognitive impairment are often unable to provide self-reports on the quality and severity of pain they experience, and when they do self-report pain, their reports may be unreliable.

Because there are inadequate strategies to assess pain in cognitively impaired elderly populations, there are few investigations evaluating the efficacy of analgesics and other palliative interventions in elders with cognitive impairments (6). As an alternative to self-report of pain, nonverbal pain expressions can be employed. Nonverbal pain displays include facial reactions, paralinguistic vocalizations and body movements. These have been shown to be useful indexes of pain (7-9). Nonverbal expressions of pain are important even when self-report is available, but their use is paramount in situations in which self-report is lacking. Clinicians often make use of nonverbal cues based on clinical intuition and idiosyncratic experience because empirical validation of cues is often not available. In consequence, judgements of pain severity and the need to provide relief are affected by factors that are irrelevant to the pain experience (eg, 10,11). The potential for bias and inadequate management of pain underlies the importance of developing objective indexes of pain that are suitable for clinical management and for use in clinical trials.

Although a broad range of nonverbal reactions is available, facial reactions have been found to be particularly useful and salient because of the range of information potentially available, visibility, rapid transmission and their reflexive nature (12). The usefulness of facial reactions in the study of pain in nonverbal populations has been established in infants $(13,14)$.

The Facial Action Coding System (FACS) (15) was designed to provide objective descriptions of facial activity. This comprehensive, atheoretical, anatomically based approach has been used extensively in research. Through its application to the study of pain, a relatively discrete pattern of facial action has been identified in both healthy volunteers and patients suffering from painful conditions (eg, 8,16,17). If the characteristic facial activity pattern of pain is identified in persons with cognitive impairments, it could serve as a tool to measure pain in these populations.

In a preliminary investigation, Hadjistavropoulos et al (18) examined the use of facial expressions as an index of pain in hospitalized frail elders who were thought to have significant cognitive impairments. Patients were videotaped while undergoing intramuscular immunization injections. The investigators found that facial reactions, coded using FACS and nurses' global impressions of perceived pain, showed the expected changes from baseline to needle penetration. That preliminary study, however, had several limitations. Specifically, the injection was visible on the film, and the judges' (ie, nurses') ratings could have been affected by viewing the needle. Second, the cognitive functioning of the patients was not assessed directly but was inferred from chart diagnoses. Third, the reactions of the participants who were thought to have significant cognitive impairments were not compared directly with those of patients who did not have such impairments.

The present study was designed to overcome all of these limitations. Consequently, patient cognitive status was assessed directly, only the patients' faces were visible on the videotape and the reactions of patients with cognitive impairments were contrasted to reactions of those without such impairments.

In the Hadjistavropoulos et al (18) study, patients' pain reactions were assessed objectively using the FACS and also by nurse observers. In the present investigation, the use of the FACS and nurses' ratings were maintained. We also included, however, a group of university student observers in order to determine whether professional training and experience in nursing relates to the way pain is perceived.

Patients' faces were filmed while they were undergoing venepuncture as part of routine blood sampling procedures. Facial reactions were videotaped during baseline (ie, a quiet interval of time), swabbing (done to cleanse the skin) and venepuncture. The reactions during swabbing were of interest because swabbing entails the essential elements of venepuncture with the exception of the invasive procedure.

It was hypothesized that elders with cognitive impairments would show facial reactions to venepuncture similar to those of elders without cognitive impairments. It was further hypothesized that facial activity would show significant in- 
creases from baseline to venepuncture. Finally, it was hypothesized that pain would be rated differently by nurse observers than by university students because routine exposure to patient pain might affect sensitivity to pain-related cues.

\section{PATIENTS AND METHODS}

Participants: Participants were 30 male and 29 female inpatients with a mean age of 73 years $(\mathrm{SD}=6.9)$. Thirty-seven patients had neurological diagnoses (eg, cerebrovascular accidents or Parkinson's disease) and 24 had diagnoses involving the musculoskeletal system or other pain-related diagnoses (eg, arthritis). Based on previously established (19) cut-off scores (less than 78), patient scores of the Modified Mini Mental Status Examination (3MS) (20), which was administered for this study, were used to classify patients as either having or not having significant cognitive impairments. Twenty-four participants were classified as having significant cognitive impairments (mean 3MS score of 38.33, $\mathrm{SD}=32.64$ ). The mean $3 \mathrm{MS}$ score for those who were not classified as having significant cognitive impairments was 86.64 ( $\mathrm{SD}=5.59)$. Nineteen participants had received analgesic medications the day that they participated in the study.

\section{Observers}

Ten nurses volunteered their time and rated perceived pain while observing the videotaped reactions of the participants during baseline, swabbing and venepuncture. Visual analogue scales (VAS) (21) were used for this purpose. All volunteer nurses were female. Interrater reliability was very good (0.80). Similarly, a group of 10 female university students provided pain ratings in the same manner as the nurses. The students' interrater reliability was also very good (0.88).

\section{Measures}

FACS: The FACS provides reliable and valid descriptors of all possible facial movements and minimizes the use of subjective judgement (15). Using explicit, rigorous criteria, the trained coder (qualified by passing a test supervised by the developers of the system) identifies and discriminates among 44 separate action units (AUs) with the aid of slow-motion or stop-action video-editing equipment. Examples of such AUs include tongue show, inner eye brow raise, tight lids and blink. Both the intensity and frequency of facial activity are coded. The validity and reliability of the system have been demonstrated repeatedly in pain research (eg, 8,17,22).

Coloured visual analogue scale: The coloured visual analogue scale (CAS), a modified version of the VAS, was developed to provide a practical clinical measure for young children with marginal self-report skills and was found to be easier to administer than the standard VAS (23). VAS has been used extensively with elders (24), but modifications may facilitate use by persons who have cognitive deficits. Pain was rated on the CAS by moving a plastic glide along a

\begin{tabular}{|c|c|c|c|}
\hline & $\begin{array}{c}\text { Baseline } \\
\text { Mean } \pm \text { SD }\end{array}$ & $\begin{array}{l}\text { Swabbing } \\
\text { Mean } \pm \text { SD }\end{array}$ & $\begin{array}{l}\text { Venepuncture } \\
\text { Mean } \pm \text { SD }\end{array}$ \\
\hline Nurses' pain ratings & $1.77 \pm 0.91$ & $2.02 \pm 1.06$ & $2.54 \pm 1.51$ \\
\hline Students' pain ratings & $1.71 \pm 0.88$ & $1.94 \pm 1.30$ & $2.92 \pm 1.75$ \\
\hline $\begin{array}{l}\text { Overall frequency of } \\
\text { facial activity }\end{array}$ & $5.72 \pm 3.69$ & $6.50 \pm 4.28$ & $7.35 \pm 5.71$ \\
\hline $\begin{array}{l}\text { Average intensity of } \\
\text { facial activity }\end{array}$ & $0.20 \pm 0.16$ & $0.22 \pm 0.15$ & $0.32 \pm 0.32$ \\
\hline $\begin{array}{l}\text { Self-reported pain rating } \\
\text { (for those capable of } \\
\text { self-report) }\end{array}$ & $0.81 \pm 1.87$ & & $2.25 \pm \pm 2.37$ \\
\hline $\begin{array}{l}\text { Self-reported pain } \\
\text { rating* (for all } \\
\text { participants) }\end{array}$ & $0.67 \pm 1.71$ & & $1.83 \pm 2.31$ \\
\hline \multicolumn{4}{|c|}{$\begin{array}{l}\text { *Scores of participants who were unable to provide a self-reported pain } \\
\text { rating were assigned a zero to indicate that no pain was reported }\end{array}$} \\
\hline
\end{tabular}

$14.5 \mathrm{~cm}$ long grid, varying in width and colour from $1 \mathrm{~cm}$ wide and a light pink colour at the bottom, to $3 \mathrm{~cm}$ wide and a deep red colour at the top. The ends of the scale are anchored with the words "No Pain" (bottom) to "Most Pain" (top). Participants are thus presented with visible cues for scaling pain severity: length of the scale and anchoring words, along with variations in width and changes in hue from pink to red. The plastic scale has numbers marked on the back so that the person administering it can record a number (ranging from 0 to 10) to represent the participant's pain. This CAS approach to pain assessment has been found to be reliable and to satisfy validity criteria when used with children (23).

\section{Procedure}

Patients' faces were videotaped during a routine blood sampling procedure. Immediately before the filming, patients were asked to indicate, using the CAS, how much pain they felt in the site where the needle penetration was to take place. Use of the scale was explained carefully, and the procedure was demonstrated until the patient indicated that she or he understood the procedure or until it became apparent that the patient was not be able to comprehend the instructions. Patients were also asked to provide a pain rating immediately following the blood sampling procedure in order to indicate how painful they perceived the procedure. Practical considerations prevented the authors from obtaining self-report pain ratings immediately following the swabbing done to cleanse the skin. Eleven patients were unable to provide self-report ratings because they had difficulty following the instructions.

Baseline, swabbing and needle penetration segments were videotaped for each patient. The three segments were randomized in a videotape of all patients so that the coder of the facial expressions did not have any prior expectations about which was an injection segment. Five seconds of baseline, $5 \mathrm{~s}$ 


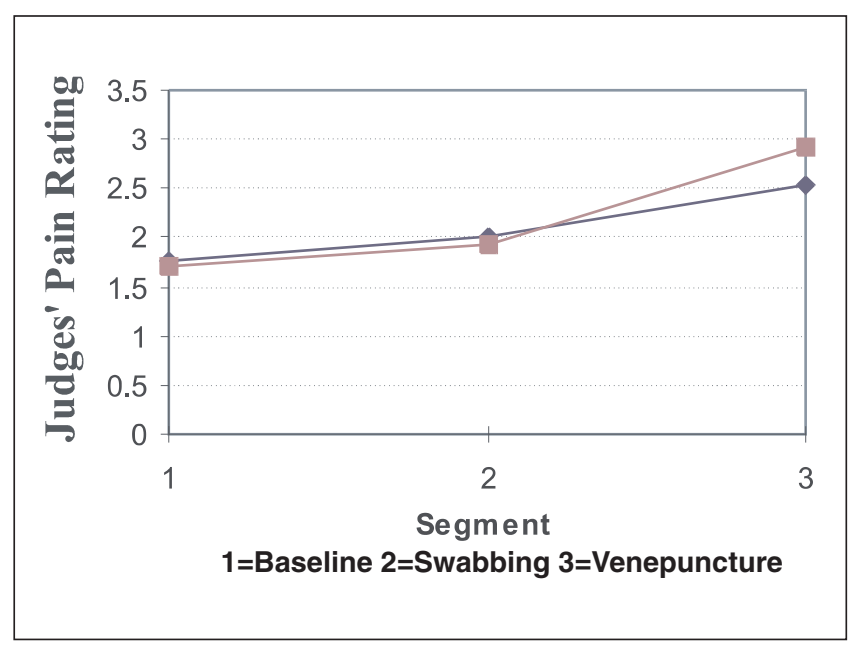

Figure 1) Judges' ratings of pain. Square Students' pain ratings; Diamond Nurses' pain ratings

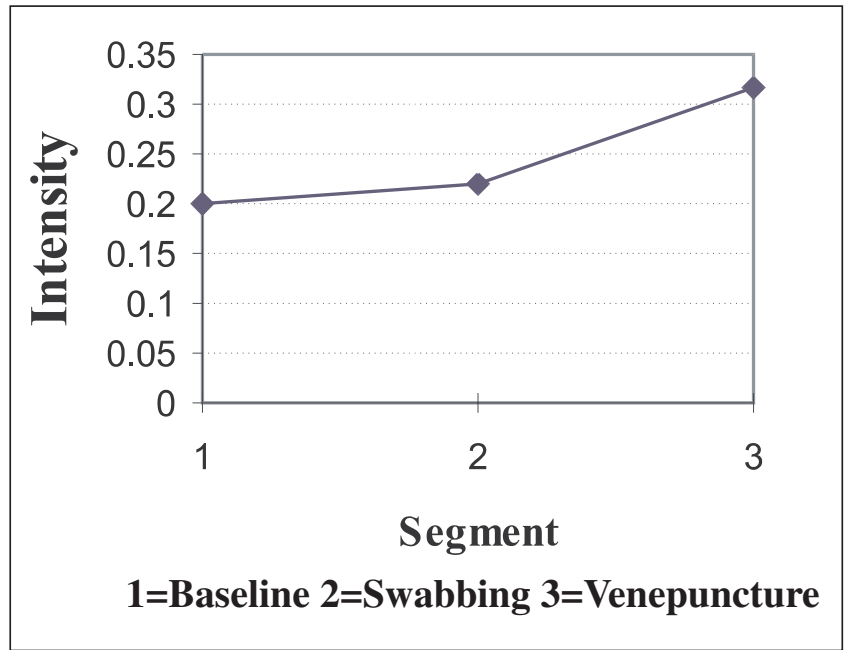

Figure 2) Intensity of facial action

of swabbing of the skin and $5 \mathrm{~s}$ commencing immediately after the needle penetration were selected for analysis. Recent research suggests that this $5 \mathrm{~s}$ interval is optimal when studying pain resulting from needle penetration (25). The audio portion was masked so that verbal indexes did not allow raters to ascertain the order of segments.

To provide measures of pain using the objectively coded facial measure, the qualified FACS coder identified the frequency and intensity of each facial movement observed within each segment. The frequencies that occurred within each of the three patient segments were added to calculate a total frequency score for each segment (ie, three total frequencies per patient). As per FACS instructions, most AUs were also rated on a five-point intensity scale that varied from minimal (score of 1) to maximal action (score of 5). Some AUs (AU11, AU25, AU26, AU27, AU38, AU39 and AU45) (eg, blink) did not lend themselves to intensity coding and were coded only for frequency. An average intensity score was also calculated by averaging the intensity of all AUs within that segment.

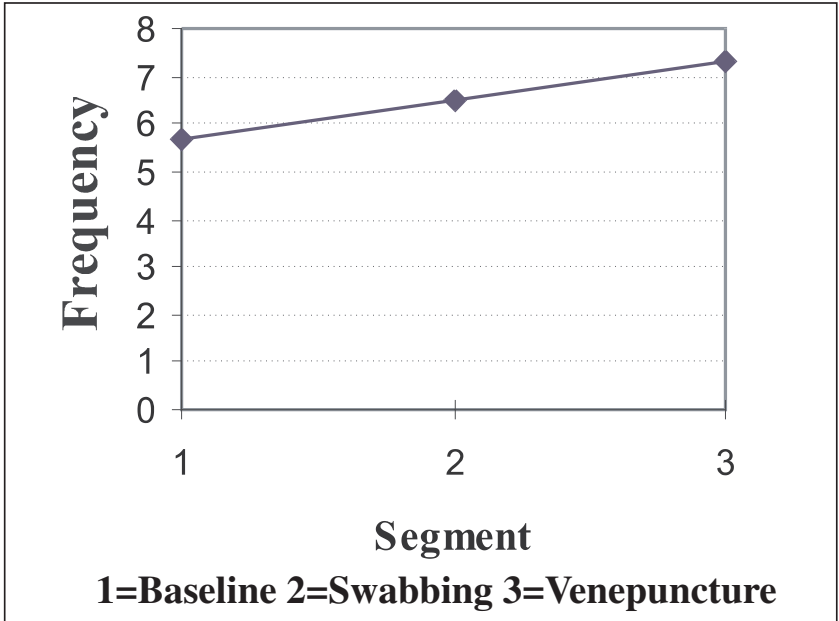

Figure 3) Overall frequency of facial action

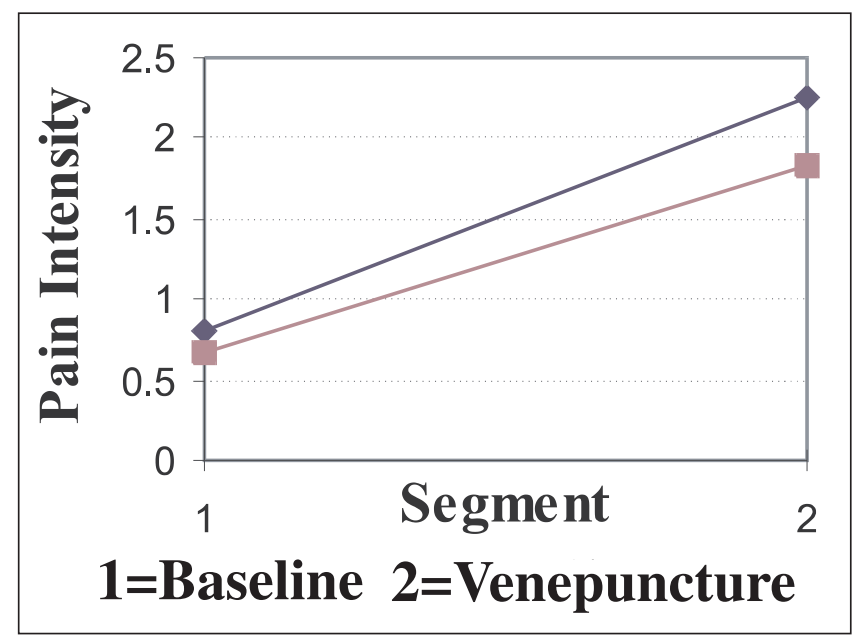

Figure 4) Self-reported pain intensity. Square Score of those unable to self-report were set to zero; Diamond Individuals capable of selfreporting provided their own score

\section{RESULTS}

The reactions of patients who did and did not receive analgesic medications on the day of the blood sampling were compared. This preliminary comparison failed to reveal any significant differences in facial reactions. Furthermore, preliminary analyses failed to reveal any significant differences in age and education between patients who were classified as having significant cognitive impairments and those who were not.

The means and SDs for the measures of objectively coded facial expression, observer-rated and self-reported pain are presented on Table 1. Figures 1 to 4 illustrate the data graphically.

A two-between (patients with significant cognitive impairments versus patients without significant cognitive impairments) by three-within (baseline versus swabbing versus venepuncture) MANOVA was used to assess changes in overall frequency and intensity of objectively coded and observer-rated facial reactions. The omnibus analysis was significant using Wilks criterion for the within-subjects 


\begin{tabular}{|c|c|c|c|c|c|c|}
\hline & Nurses' ratings & Students' ratings & Self-report ${ }^{\dagger}$ & Self-report ${ }^{\ddagger}$ & FACS frequency & FACS intensity \\
\hline Nurses' ratings & 1.0 & & & & & \\
\hline Student's ratings & $0.833^{* *}$ & 1.0 & & & & \\
\hline Self-report $^{\dagger}$ & $0.483^{* *}$ & $0.268^{*}$ & 1.0 & & & \\
\hline Self-report $^{\ddagger}$ & $0.349^{*}$ & 0.140 & & 1.0 & & \\
\hline FACS frequency & $0.725^{* *}$ & $0.617^{* *}$ & 0.263 & 0.195 & 1.0 & \\
\hline FACS intensity & $0.681^{* *}$ & $0.601 * *$ & 0.074 & 0.127 & $0.855^{* *}$ & 1.0 \\
\hline
\end{tabular}

A total of 53 patients (who had complete data) are represented in the correlations involving most variables. The correlations involving the self-report of patients who provided it are based on 43 cases. ${ }^{*} P \leq 0.05 ;{ }^{* *} P \leq 0.01 ;{ }^{\dagger}$ Self-report for individuals capable of providing self-report; ${ }^{*}$ Self-report for individuals not capable of providing self-report were set to zero to reflect that no pain was reported. FACS Facial Action Coding System

effect $(\mathrm{F}[8,194]=4.83, \mathrm{P}<0.001)$. Consistent with our hypotheses, facial activity increased from baseline to the venepuncture segment (Table 1). Follow-up univariate analyses suggested that there were highly significant increases in the intensity of facial activity from baseline to venepuncture $(\mathrm{F}[2,100]=4.78, \mathrm{P}=0.01)$.

Planned comparisons using the least significant difference method revealed that FACS intensity during the venepuncture segment was significantly higher than that during the swabbing $(\mathrm{t}[52]=2.23, \mathrm{P}<0.02)$ and baseline $(\mathrm{t}[52]=2.60$, $\mathrm{P}<0.02)$ segments. The baseline and swabbing segments were not significantly different from each another. The follow-up univariate analyses of the total frequency of facial activity provided results that approached but did not reach statistical significance $(\mathrm{F}[2,100]=2.52, \mathrm{P}<0.09)$. The univariate analyses on the students' $(F[2,100]=16.47, \mathrm{P}<0.001)$ and the nurses' ratings $(\mathrm{F}[2,100]=5.89, \mathrm{P}<0.004)$ were both significant. The least significant difference method suggested that both the nurses and the students rated the venepuncture segments as being more painful than both the swabbing $(\mathrm{ts}[1,53]>2.23$, ps $<0.02)$ and the baseline segments (ts $[1,53]>3.25$, ps $<0.001)$. The MANOVA did not reveal any significant differences in groups of subjects varying in cognitive functioning or interaction effects.

A separate two-way (ie, level of cognitive functioning) ANOVA with two repeated measures was applied on the self-report pain rating obtained during baseline and immediately following the venepuncture. Persons unable to provide self-reports of pain were given a score of zero to indicate that no pain was reported. The analyses revealed that the main within-subjects effect was significant $(F[52,1]=23.02$, $\mathrm{P}<0.0001$ ). The analysis did not reveal a significant betweensubject effect.

Following precedents in the literature (eg, 26), the AUs that occurred more than $5 \%$ of the time during the pain segment were examined to determine whether they were specifically associated with pain. These were AU1 (inner brow raise), 4 (brow lower), 7 (lids tight), 17 (chin raise) and 45 (blink). The difference in the frequency of AU4 across the baseline, swabbing and venepuncture conditions was signifi$\operatorname{cant}(\mathrm{F}[2,116]=4.02, \mathrm{P}<0.02)$, and the least significant differ- ence method showed that, as expected, AU4 occurred more frequently during the venepuncture segment than during the baseline and swabbing segments (ts[58]>1.99, $\mathrm{P}<0.05)$, which were not different from one another. None of the other AUs that occurred more than 5\% during the pain segment differed significantly across segments.

An examination of the intensities of these five AUs revealed that the intensity of AU4 $(\mathrm{F}[2,116]=5.15, \mathrm{P}<0.007)$ and AU17 $(\mathrm{F}[2,116]=3.13, \mathrm{P}<0.05)$ varied significantly across segments. The Least Significant Difference method revealed that the intensity of AU4 was greater during the venepuncture segment than during the swabbing and baseline segments (ts[58]>2.38, ps<0.02), which were not different from one another. Similar effects were found for AU17 (ts[58]>1.98, ps<0.05).

Nurses' and students' pain ratings were compared by using paired samples $t$ tests. Although the nurses and students rated the baseline and swabbing segments in a similar fashion, the students rated the venepuncture segments as significantly more painful than did the nurses $(\mathrm{t}[52]=2.89$, $\mathrm{P}<0.006)$. It is worth noting that these pain ratings were not related to the age of the nurses and students.

Table 2 presents the intercorrelations among the various pain indexes. To determine the extent to which the students' and the nurses' ratings during the venepuncture segment were affected by the frequency and/or intensity of facial activity, the authors conducted regression analyses using both frequency and intensity of facial activity as predictors. The analyses of nurses' ratings resulted in a significant full regression model $(\mathrm{F}[2,49]=27.98, \mathrm{P}<0.0001)$, accounting for $53 \%$ of the variance in the nurses' ratings. An examination of the unique contribution of each independent variable (after entering the other predictor in the equation) suggested that frequency, but not intensity, of facial activity made a significant and unique contribution of an $\mathrm{R}^{2}$ change of 0.07 $(\mathrm{F}[1,49]=7.31, \mathrm{P}<0.01)$.

A similar analysis of the students' ratings resulted in a significant full model $(\mathrm{F}[2,49]=16.24, \mathrm{P}<0.0001)$ and accounted for approximately $40 \%$ of the variance. Neither the frequency nor the intensity of overall facial activity made unique contributions to the prediction. 
Finally, a regression analysis relating patient self-report (where available) to the frequency and intensity of FACS variables during the pain segment revealed a significant full model accounting for $20 \%$ of the variance $(F[2,40]=5.11$, $\mathrm{P}<0.01)$. Both the frequency and intensity of facial activity made significant unique contributions to the prediction, with frequency contributing an $R^{2}$ change of $0.21(F[1,40]=9.95$, $\mathrm{P}<0.003$ ) and intensity contributing an $\mathrm{R}^{2}$ change of 0.11 $(\mathrm{F}[1,40]=6.64, \mathrm{P}<0.01)$.

\section{DISCUSSION}

Our results underscore the importance of being attentive to nonverbal expressions when caring for patients with cognitive impairments. It is notable that a substantial portion of this sample of hospitalized elders was incapable of selfreport.

We incorporated several improvements in design, and our findings extend and replicate those of Hadjistavropoulos et al (18). Facial reactions appear to be useful indexes of pain for hospitalized frail elders regardless of whether they are assessed by the FACS or by observers, although in clinical settings judgements can be biased by irrelevant factors $(10,11)$. These indexes appear to be useful regardless of whether the elders are identified as having significant cognitive impairments. This usefulness seems to be especially true for intensity of facial reaction rather than frequency, although the increases in frequency also approached statistical significance. AUs 4 (brow lower) and 17 (chin raise) seem to be of special interest in this context because they were found to occur more frequently and/or appear to be more pronounced in the pain segment than during the baseline and swabbing segments. These AUs have been found to be characteristic of pain in other studies $(17,25)$. Nonetheless, the primary characteristic of pain in this context appears to be an overall increase in the intensity of overall facial activity. Perhaps in situations where the painful stimulus is stronger than it was in this investigation (eg, during more invasive medical procedures or severe distress) a more distinct facial expression would emerge.

The FACS-based indexes correlated highly with both the students' and the nurses' ratings, and support the position that facial reactions are useful indexes of pain. This finding is encouraging with respect to the use of untrained observers in studies involving facial reactions to pain. The student ob-

\section{REFERENCES}

1. Biersdorff KK. Pain insensitivity and indifference: Alternative explanations for some medical catastrophes. Ment Retard 1991;29:359-62.

2. Mobily PR, Herr KA, Clark MK, Wallace RB. An epidemiological analysis of pain in the elderly: The Iowa 65+ Rural Health Study. J Aging Health 1994;6:139-54.

3. Roy R, Thomas M. A survey of chronic pain in elderly populations. Can Fam Physician Med Fam Can 1986;32:513-6.

4. Sengstaken EA, King SA. The problems of pain and its detection among geriatric nursing home residents. J Am Geriatr Soc 1993;41:541-54.

5. Parmelee PA, Smith B, Katz IR. Pain complaints and cognitive status among elderly institution residents. J Am Geriatr Soc 1993;41:517-22. servers perceived more pain than the nurse observers did during the venepuncture segment, which may reflect an oversensitivity to pain reactions that might have been manifested by the student observers. The nurses may have not displayed such oversensitivity because repeated exposure to a situation (eg, injections or venepuncture) reduces the emotional response to it (27). The nurses' ratings were more consistent with the patients' self-reports and could, perhaps, carry more validity. Hadjistavropoulos et al (18) found that nurses' ratings of pain were more affected by the intensity rather than frequency of facial reactions. In the present study, frequency appeared to make unique contributions (ie, over and above intensity) to the prediction of the nurses' ratings. It is possible that when the medical procedure is visible on film, as occurred in the Hadjistavropoulos et al study (18), less attention is directed to the frequency of facial activity. In contrast, when nurses are trying to infer pain in the absence of cues other than a facial expression, they may be paying special attention to the frequency of facial reactions.

Our data also support the validity of self-report, when this is available, as an index of pain for this sample of hospitalized elders. Specifically, our regression analysis showed self-report to be related to the FACS-based indexes of pain. Nonetheless, the utility of self-report varies depending on the degree to which a patient has cognitive impairments (ie, nature of the sample).

Given that palliative interventions for persons with cognitive impairments have been underresearched, partly because of the challenges of measuring pain in these populations, the findings of the present study suggest that facial indexes of pain can serve as proxy when self-report is unavailable. They can also be used to supplement self-report when it is available. While FACS-based indexes of pain are not amenable for use in day-to-day pain assessments, they are uniquely suited to serve as outcome measures within the context of clinical trial methodology. It is hoped that this paper will help stimulate that research. It is also possible that training observers to use facial activity as cues to pain will improve their use of nonverbal assessments.

ACKNOWLEDGEMENTS: This paper was supported in part by a Health Services Utilization and Research Commission grant to Thomas Hadjistavropoulos.

6. Ferrell PR, Ferrell BA, eds. Pain in the Elderly. Seattle: IASP Press, 1996.

7. Craig KD, Prkachin KM, Grunau RVE. The facial expression of pain. In: Turk D, Melzack R, eds. Handbook of Pain Assessment. New York: Guilford Press, 1992:257-76.

8. Hale C, Hadjistavropoulos T. Emotional components of pain. Pain Res Manage 1997;2:217-25.

9. Keefe FJ, Block AR. Development of an observation method for assessing pain behavior in chronic low back pain patients. Behavior Therapy 1982;13:363-75.

10. Hadjistavropoulos T, McMurtry B, Craig KD. Beautiful faces in pain: Biases and accuracy in the perception of pain. Psychol Health 1996;64:435-43. 
11. Hadjistavropoulos HD, Ross M, von Baeyer C. Are physicians' ratings of pain affected by patient physical attractiveness? Soc Sci Med 1990;31:69-72.

12. Ekman P, Friesen W. The repertoire of nonverbal behavior: Categories, origins, usage and coding. Semiotica 1969:1:49-98.

13. Craig KD, Grunau RVE. Neonatal pain perception and behavioral measurement. In: Anand KIS, McGrath PI, eds. Neonatal Pain and Distress. Amsterdam: Elsevier Science, 1993.

14. Craig KD. The facial display of pain. In: Finley GA, McGrath PI, eds. Measurement of Pain in Infants and Children. Seattle: IASP Press, 1998:103-22.

15. Ekman P, Friesen W. Investigator's guide to the Facial Action Coding System. Palo Alto: Consulting Psychologists Press, 1978.

16. Craig KD. The facial expression of pain: Better than a thousand words? Am Pain Soc J 1992;1:153-62.

17. Prkachin K. The consistency of facial expressions of pain: A comparison across modalities. Pain 1992;35:71-8

18. Hadjistavropoulos T, Craig KD, Martin N, Hadjistavropoulos H, McMurtry B. Toward a research outcome measure of pain in frail elderly in chronic care. Pain Clinic 1997;10:71-9.

19. Canadian Study on Health and Aging Working Group. Canadian Study of Health and Aging: Study methods and prevalence of dementia. Can Med Assoc J 1994;150:899-13.

20. Teng EL, Chui HC. The Modified Mini-Mental State (3MS) examination. J Clin Psychiatry 1987;48:314-8.

21. Turk D, Melzack R, eds. Handbook of Pain Assessment. New York: Guilford Press, 1992.

22. Craig KD, Hyde S, Patrick CJ. Genuine, suppressed and faked facial behavior during exacerbation of low back pain. Pain 1991;46:161-71.

23. McGrath PA, Seifert CE, Speechley KN, et al. A new analogue scale for assessing children's pain: An initial validation study. Pain 1996;64:435-43.

24. Harkins SW, Price DD. Assessment of pain in the elderly. In: Turk D, Melzack R, eds. Handbook of Pain Assessment. New York: Guildford Press, 1992:315-31.

25. LaChapelle D, Hadjistavropoulos T, Craig KD. Pain measurement in individuals with intellectual disabilities. Pain Res Manage 1998;3:41. (Abst)

26. Hadjistavropoulos HD, Craig KD, Hadjistavropoulos T, Poole G. Subjective judgements of deception in pain expression: Accuracy and errors. Pain 1996;65:251-8.

27. Rachman S. Anxiety. East Sussex: Psychology Press Ltd, 1998. 


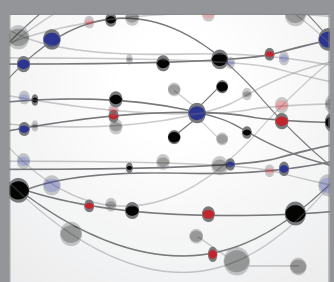

The Scientific World Journal
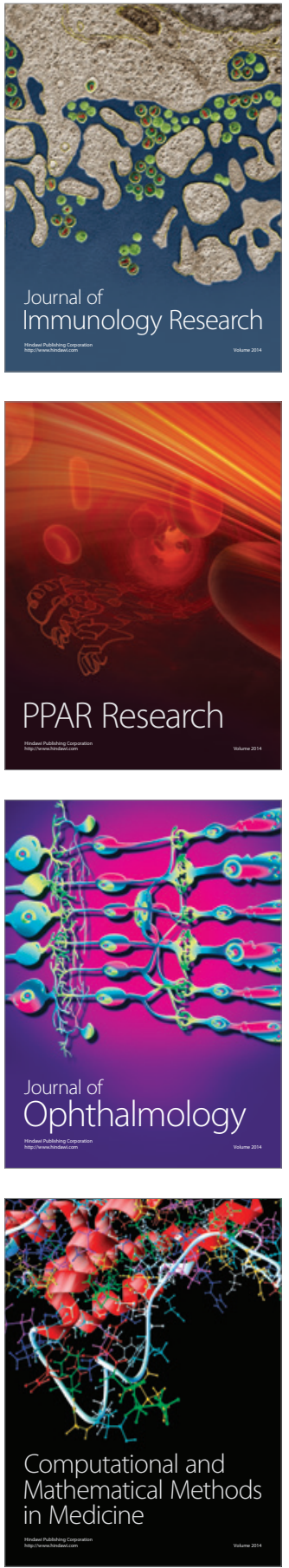

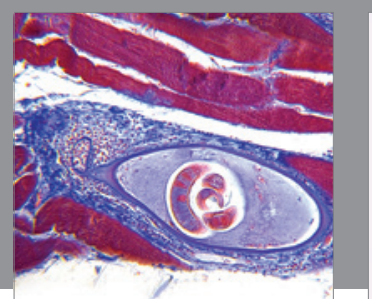

Gastroenterology Research and Practice

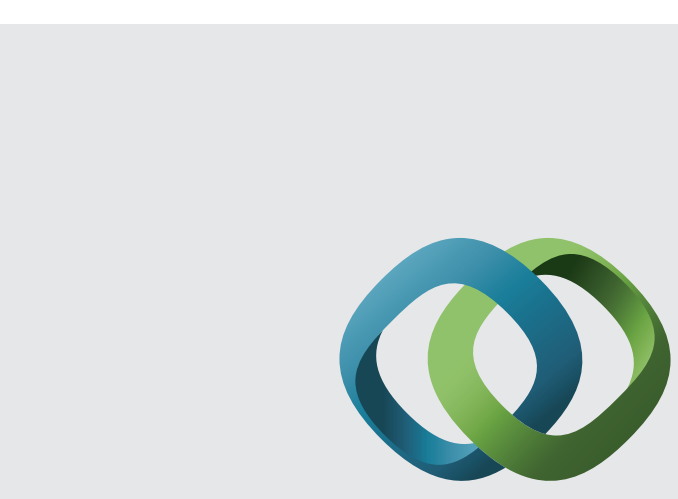

\section{Hindawi}

Submit your manuscripts at

http://www.hindawi.com
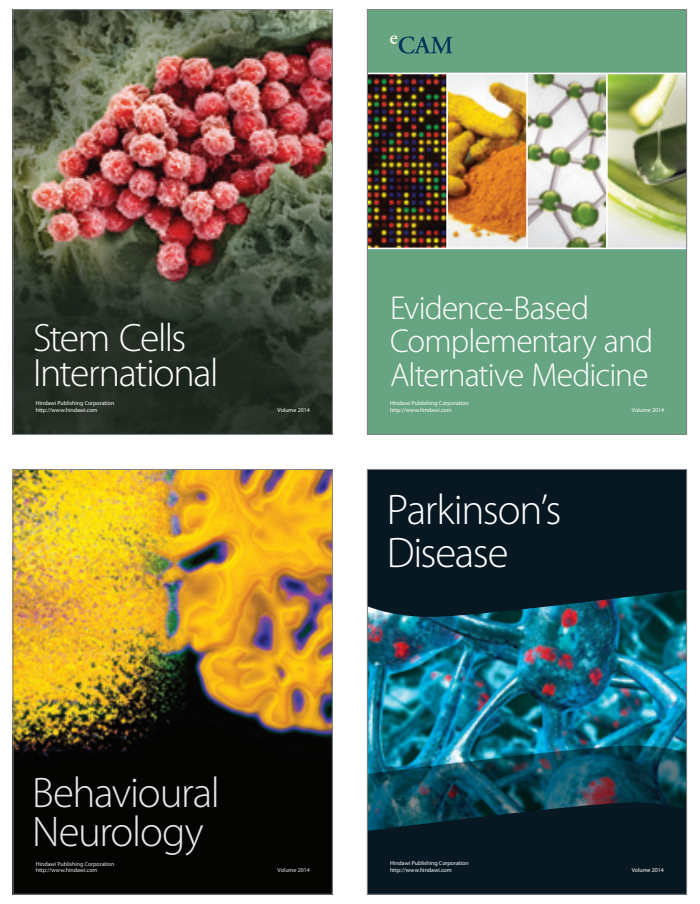
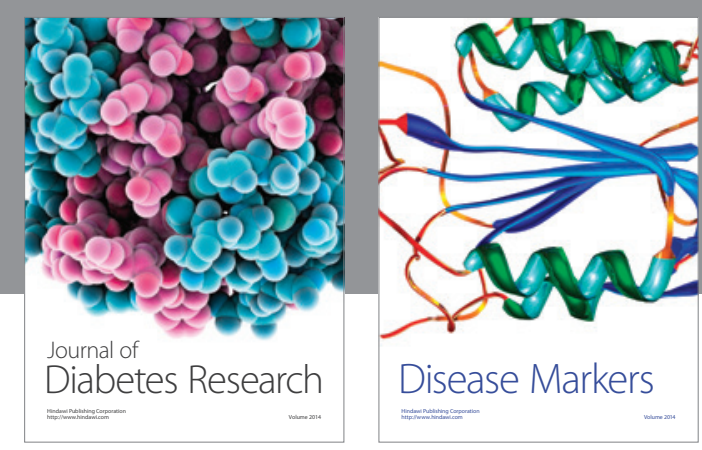

Disease Markers
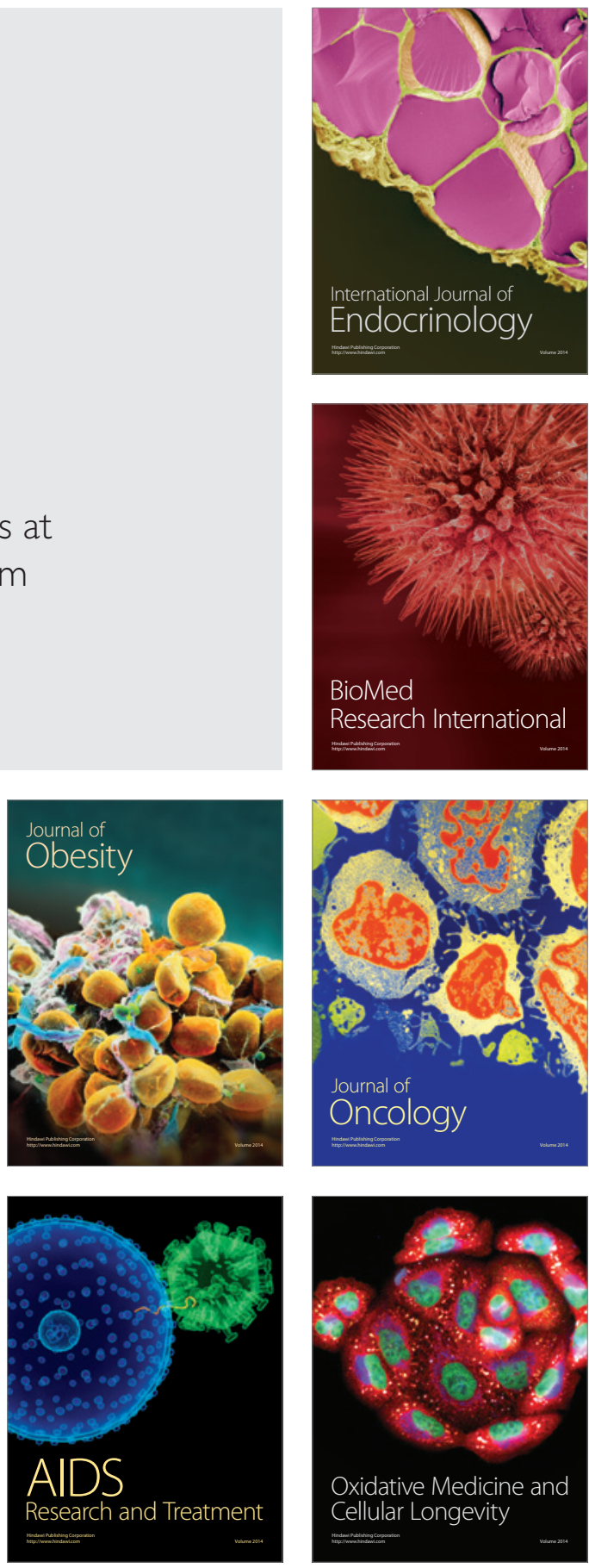